ORIGINAL ARTICLE

\title{
The Association between Obesity and Prostate Volume in Patients with Benign Prostatic Hyperplasia
}

\author{
IJAZ UR REHMAN ${ }^{1}$, SYED ATIF HUSSAIN², HUMAYUN KHAN ${ }^{3}$, BILAL HABIB ${ }^{4}$, RAHEEL SHEIKH ${ }^{5}$ \\ ${ }^{1}$ Assistant Professor Urology, Department of Urology Gomal Medical College Dera Ismail Khan KPK Pakistan \\ ${ }^{2}$ Assistant Professor Urology Sheikh Zayed Medical College/Hospital Rahim Yar Khan \\ ${ }^{3}$ Senior Registrar Urology, Abbottabad International Medical Institute, Abbottabad \\ ${ }^{4} P G R$ Urology, PAEC hospital, Islamabad \\ ${ }^{5}$ MBBS, FACS, FRCS, FCPS (Surgery), FCPS (Urology) Consultant Surgeon and Urologist Margalla Hospital, Taxila \\ Corresponding author: Dr ljaz ur Rehman, E-mail: dr.ejazmarwat@gmail.com, Contact No. +923339971995
}

\begin{abstract}
Background and Aim:Prostate histological enlargement known as Benign Prostatic Hyperplasia (BPH) is the major challenge for aging men with substantial burden on the health care system. It is associated with incomplete emptying sensations and impedance in flow due to symptoms of the lower urinary tract. Patient of higher body mass index (BMI) or obese have larger prostate volume (PV) and increase in lower urinary tract symptoms (LUTS) compared to normal BMI patient as reported by many researchers. The current study aim was to correlate the association between obesity and prostate volume in BPH patients.

Materials and Methods: This cross-sectional was conducted on $140 \mathrm{BPH}$ patients with 45 years to 75 years age range admitted in the department of Urology, DHQ Teaching Hospital, Dera Ismail Khan for six months duration from July 2020 to December 2020. BMI of each individual was calculated using height and weight measurements. Measuring tape was used to measure waist circumference (WC) while Prostate volume (PV) was measured with Transrectal Ultrasound (TRUS). Demographic and clinical parameters such as diabetes, smoking, prostate specific antigen (PSA) and hypertension were recorded on pre-designed proforma. Outcome variables were BMI and prostate volume.

Results:Patients were divided into three categories based on BMI namely Obese, overweight and normal. Mean value for age and BMI was $61.34 \pm 5.324$ and $26.89 \pm 4.13$ respectively. Mean PV of Obese, overweight and normal BMI were $61.34 \pm 7.5,59 \pm 3.10$ and $50.91 \pm 8.5 \mathrm{~cm}^{3}$ respectively. The PV average score was $58.42 \pm 6.53 \mathrm{~cm}^{3}$. The mean value for waist circumference (WC) and PSA were 97.20 and 5.10 \pm 3.23 with 1.2-5.9 range respectively. The correlation between PV and BMl as well as between WC and PV, diabetes, smoking and hypertension shown no significance ( $p$ value $=0.195$ ). However, PSA and PV correlation give significant ( $p$ value 0.001-0.009) correlation.

Conclusion:Central obesity plays a key role in developing and promoting BPH. The highest prevalence of BPH was found in patients with $\mathrm{BMI}>30 \mathrm{~kg} / \mathrm{m} 2$ while lowest in men of $\mathrm{BMl}<23 \mathrm{~kg} / \mathrm{m} 2$. The current study found higher frequency of BPH among patients with WC $>90 \mathrm{~cm}$ and lowest in men of $W C<90 \mathrm{~cm}$. A positive correlation was found between WC, BMI and PV. Individual quality of life affected by LUTS caused by severe risk of BPH due to increase in obesity. Balance diet and physical exercise help in maintaining the healthier BMI among obese and aged men.
\end{abstract}

Keywords: Benign prostate hypertrophy, Bladder outlet obstruction, Prostate volume

\section{INTRODUCTION}

Benign Prostatic Hyperplasia is the irregular enlargement of the prostate gland most common and appears in aging men $[1,2]$. Prostate tissue failure causes apoptosis with increasing prostate gland size and advancement in age [2] Men in the age above 40 years or having fifth decade are more susceptible to $\mathrm{BPH}[3,4]$. Prostate size provides a presumptive base for $\mathrm{BPH}$ diagnosis [5]. BPH and neoplasm mainly occurs in obese and old aged (above 40 years) men [6-8]. Lower Urinary Tract Symptoms (LUTS) caused by BPH development had higher probability in patients with advancing age. LUTS involve a set of symptoms like dysuria, urgency, post-void dibbling, nocturia, incontinence overflow and urinary frequency [9]. Prostate enlargement caused the prostate transitional zone around the urethra [10]. The major challenge for the health care system is the extensive burden of most common BPH development in older men. It is estimated that patients (men) having more than 60 years of age had a BPH proportion of about $75 \%$ [11]. The advancement in age and increase in prostatic growth causes higher prevalence of obesity [12]. Many researchers reported direct relation of obesity and BPH. BPH caused by intravesical pressure is due to obesity which increases the intra-abdominal pressure. Nocturia, hesitancy and poor stream of urine are the few key symptoms of BPH [13].

$\mathrm{BPH}$ favorable parameters like oxidative stress and ischemic are caused by inflammation and micro-vascular disease due to increase in central obesity [14]. Pro-growth cytokines and other growth variables are caused by chronic inflammation [15]. Increase in estrogen to androgen ratio causes endocrine status alteration as reported by another hypothesis. The androgen to estrogen conversion and aromatase activity increase are mainly due to dipose tissue increase which in turn reduces the testosterone levels by gonadotropins suppression which favors the BPH development [16]. Many literature classified criteria for patients BMI and WC for obesity diagnosis and outcomes. Their result demonstrated that obesity plays key role in LUTS worsening and increase in BPH development risk [17-22]. Inflammation caused by hormonal acceleration and systemic changes are due to the dominance of central 
obesity over general obesity in correlation with $\mathrm{BPH}$ development [15].

In BPH patients, prostate gland volume is significantly influenced by central obesity as a major determination's factor [17]. Obesity is defined by BMI value for example BMI between $18.5 \mathrm{~kg} / \mathrm{m}^{2}$ and $22.9 \mathrm{~kg} / \mathrm{m}^{2}$ is normal while above $25 \mathrm{~kg} / \mathrm{m}^{2}$ is considered as obese [18, 19]. It has been observed that prostate volume increases $0.41 \mathrm{~mL}$ as $\mathrm{BMI}$ increases by $1 \mathrm{~kg} / \mathrm{m}^{2}$. Mode of treatment selection is based on prostate volume sonographic assessment which categorized the normal prostate volume below $25 \mathrm{~mL}$ [20]. It has been reported in many patients of $\mathrm{BPH}$ having more than $30 \mathrm{~mL}$ prostate volume providing evidence to hypothesis that obese men had higher prostate volume compared to normal weighted men [21]. Prostate volume had greater associations with abdominal obesity, waist circumference, BMI and bodyweight [22-24]. Several imaging modalities can be utilized to measure prostate volume such as Magnetic Resonance Imaging, Computed Tomography and Ultrasound. Clinically for more than 50 years Ultrasound of various kinds such as Transrectal (TRUS), Transperineal (TPUS) and Transabdominal (TAUS) had been used for prostate volume measurement [24].Rapid increase of obesity among male populations promotes benign prostatic hyperplasia. The current study will correlate the obesity and prostate volume in patients with $\mathrm{BPH}$.

\section{MATERIALS AND METHODS}

This cross-sectional was conducted on $140 \mathrm{BPH}$ patients with 45 years to 75 years age range admitted in the department of Urology, Urology, DHQ Teaching Hospital,Dera Ismail Khan for six months duration from July 2020 to December 2020. Prior to approval of the study from the ethical committee of the respective institute. Individuals meeting the inclusive criteria were enrolled in the study. $\mathrm{BPH}$ male patients having age above 40 years were enrolled. Each individual underwent a sonographic examination. The exclusive criteria were surgical intervention or TURP history, chronic prostatitis, prostate cancer, urinary tract infection, bladder stone history and neurogenic dysfunction of bladder. WHO based criteria were set to categorized the participant in following groups Healthy (> $\left.18.9 \mathrm{Kg} / \mathrm{m}^{2}-25 \mathrm{Kg} / \mathrm{m}^{2}\right)$, Obese $\left(\geq 30.0 \mathrm{~kg} / \mathrm{m}^{2}\right.$ ) and Overweight (>25.0 to $29.9 \mathrm{~kg} / \mathrm{m}^{2}$ ). BMl of each individual was calculated using height and weight measurements. Measuring tape was used to measure waist circumference (WC) while Prostate volume (PV) was measured with Transrectal Ultrasound (TRUS). Demographic and clinical parameters such as diabetes, smoking, prostate specific antigen (PSA) and hypertension were recorded on pre-designed proforma. Outcome variables were BMI and prostate volume. Normal WC $(<90$ $\mathrm{cm}$ ) and central obesity $(>90 \mathrm{~cm}$ ) were the WHO based classification for Obesity. Each participant gave their informed consent and the height, weight, BMI, and WC of each participant were recorded.Toshiba (Aplio-300) and Mindray (DP-5) ultrasound machine was used to measure the prostate volume with $3.5 \mathrm{MHz}$ curvilinear transducer. Inferior angle of the transducer under symphysis pubis and supine position for individual were followed to have better assessment. Transducer was angled at $15^{\circ}$ with feet for transverse section of the full bladder. Prostate images were captured in frozen state for measuring its length, anteroposterior diameter and transverse.

Statistical Analysis: Non-probability sampling technique was utilized for collecting the sample. Following assumption was considered for calculating the sample size, Prevalence $8 \%$, Margin of error $0.06 \%$ and confidence interval $95 \%$. SPSS version 20 was used to enter and analyze data. Numerical quantities such as frequency, percentage, mean and standard deviation were measured with $\mathrm{P}$-value of $<0.05$ was considered significant.

\section{RESULTS}

Patients were divided into three categories based on BMI namely Obese, overweight and normal. Mean value for age and BMI was $61.34 \pm 5.324$ and $26.89 \pm 4.13$ respectively. Mean PV of Obese, overweight and normal BMl were $61.34 \pm 7.5,59 \pm 3.10$ and $50.91 \pm 8.5 \mathrm{~cm}^{3}$ respectively. The $P V$ average score was $58.42 \pm 6.53 \mathrm{~cm}^{3}$. The mean value for waist circumference (WC) and PSA were 97.20 and $5.10 \pm 3.23$ with 1.2-5.9 range respectively as shown in Table 1. The correlation between PV and BMl as well as between WC and PV, diabetes, smoking and hypertension shown no significance ( $p$ value $=0.195)$. However, PSA and PV correlation give significant ( $p$ value $0.001-0.009$ ) correlation. Figure 1 shows the frequency of BMl of total participants among overweight, healthy or normal and obese.

Table 1. Descriptive Statistics of total participants $(n=140)$

\begin{tabular}{|l|l|}
\hline Parameters & $\begin{array}{l}\text { Total Participants }(\mathrm{n}=140) \text { with } \\
\text { Mean } \pm \text { SD }\end{array}$ \\
\hline Age (years) & $61.34 \pm 5.324$ \\
\hline Weight $(\mathrm{Kg})$ & $73.46 \pm 12.90$ \\
\hline Height $(\mathrm{m})$ & $1.67 \pm .13$ \\
\hline WC $(\mathrm{cm})$ & $97.20 \pm 5.9$ \\
\hline PV $(\mathrm{mL})($ Obese, & $61.34 \pm 7.5,59 \pm 3.10$ and $50.91 \pm 8.5$ \\
overweight and normal) & $\mathrm{cm}^{3}$ \\
\hline BMl & $26.89 \pm 4.13$ \\
\hline
\end{tabular}

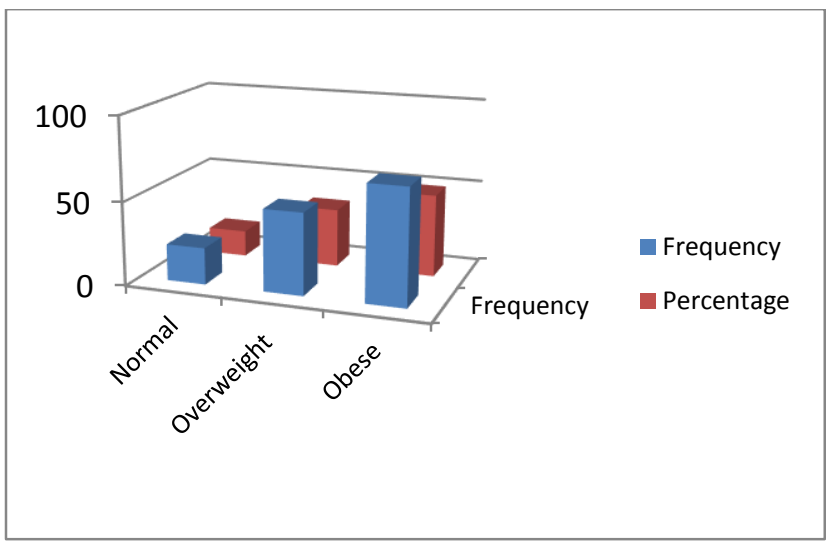

Figure 1. Prevalence of participants based on BMI

The total participants 140 distribution with mean WC value $97.20 \pm 5.9$ was as follows: 31 were having WC value less than $90 \mathrm{~cm}$ and 109 had more than $90 \mathrm{~cm}$ as shown in Table 2 and Figure 2. All subjects with $\mathrm{BMI}>30 \mathrm{~kg} / \mathrm{m} 2$ (obese) had higher WC value $(>90 \mathrm{~cm})$. 
Table 2 Prevalence of participants based on WC value measured

\begin{tabular}{|l|l|l|}
\hline WC $(\mathrm{cm})$ & Frequency $(\mathrm{n})$ & Percentage $(\%)$ \\
\hline$<90$ & 31 & 22.10 \\
\hline$>90$ & 109 & 77.90 \\
\hline Total & 140 & 100 \\
\hline
\end{tabular}

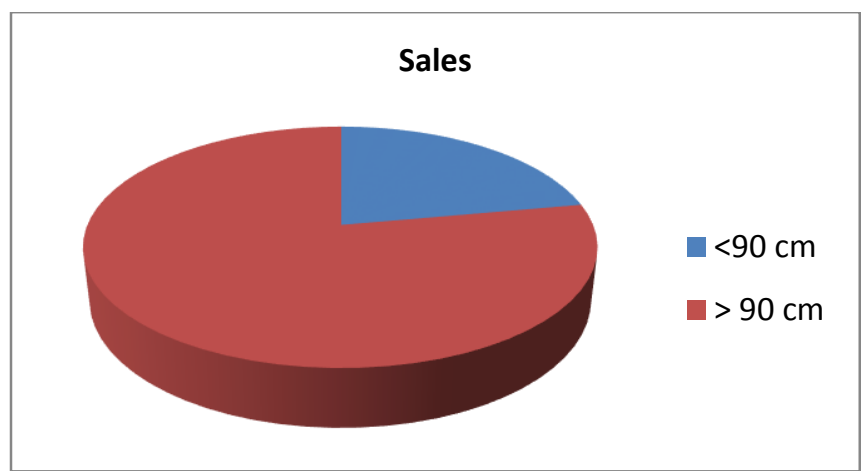

Figure 2: Frequency of Participants based on WC value.
The prostate volume mean value was $61.34 \pm 7.5 \mathrm{~mL}$. The PV maximum and minimum value was $80 \mathrm{~mL}$ and 40 $\mathrm{mL}$ respectively as shown in table 3 .

Table 3 Descriptive statistics for Prostate Volume

\begin{tabular}{|l|l|l|l|l|l|l|}
\hline & $\mathrm{N}$ & Maximum & Minimum & Range & Mean & SD \\
\hline Prostate Volume & 140 & 80 & 40 & 40 & 61.34 & 7.50 \\
\hline
\end{tabular}

\section{DISCUSSION}

$\mathrm{BPH}$ development factors include smoking, steroid hormones, aging, genetic and metabolic syndromes. Metabolic syndromes are cardiovascular disease, dyslipidemias and obesity. Participants of age above 40 years and no previous history of prostate pathology were enrolled in this study. The mean value for waist circumference (WC) and PSA were 97.20 and $5.10 \pm 3.23$ with 1.2-5.9 range respectively. Participants who had higher $\mathrm{BMI}$ and WC value have greater risk for $\mathrm{BPH}$ development as observed in this study. Obese patients were more susceptible to develop BPH. The prevalence of $\mathrm{BMI}$ in obese group had higher contribution in developing $\mathrm{BPH}$ compared to normal BMI participants. Positive significance among WC, BMI and PV were observed. Many researchers reported the basic causes for $\mathrm{BPH}$ development are WC and BMI. S. Lee and H.G Min conducted their study to determine the obesity effect on $\mathrm{BPH}$ promotion in South Korea. They concluded that the major risk factors for BPH promotion and development are higher BMI, WC and central obesity which gives positive association with prostate volume [25]. The contradictory study conducted by Iffat found irregular prostatic volume and growth with increased WC and BMI. However, Patients with more than $90 \mathrm{~cm}$ WC contributed the most in prostatic volume. She also suggested that central obesity is the risk factor for BPH development [17].

Another study conducted on association between BMI, PV, quality of life and age showed an inverse relation between quality of life and increased BMI. Their study also observed the increased prostate volume with increase in BMI [26]. J. Parson's study concluded the direct effect of physical exercise on lowering BPH. Natural course of BPH changes with changes in lifestyle [27]. The current study observed the higher risk of $\mathrm{BPH}$ development among obese patients compared to non-obese. The prostate volume enlargement is mainly caused by higher BMI and obesity in turn experiences severe urinary symptoms.
Prostate gland enlargement increases the risk for individual life quality standards. Our study observed no significant difference in prostate volume for both non-hypertensive and hypertensive patients. However, smoking, diabetes and hypertension were the most prevalent factors among the population. Our analysis matched with the study conducted by Li-Peng. According to his study BPH and hypertension had no association with each other [27]. This is in contrast to the findings of a 2013 South Korean study in which men with hypertension had a higher International Prostate Symptom Score as well as larger PV putting them at an increased risk of LUTS compared to the nonhypertensive [28].

\section{CONCLUSION}

Central obesity play key role in developing and promoting $\mathrm{BPH}$. The highest prevalence of $\mathrm{BPH}$ was found in patients with $\mathrm{BMI}>30 \mathrm{~kg} / \mathrm{m}^{2}$ while lowest in men of $\mathrm{BMI}<23 \mathrm{~kg} / \mathrm{m}^{2}$. The current study found higher frequency of $\mathrm{BPH}$ among patients with $W C>90 \mathrm{~cm}$ and lowest in men of $W C<90 \mathrm{~cm}$. A positive correlation was found between WC, BMI and PV. Individual quality of life affected by LUTS caused by severs risk of $\mathrm{BPH}$ due to increase in obesity. Balance diet and physical exercise help in maintaining the healthier BMI among obese and aged men.

\section{REFERENCES}

1. Bacha, R., Gilani, S. A., Asif, H. M., ul Hasan, Z.,Sharif, Z., Zaidi, K., ... \& Hussain, S. (2018).Sonographic Association of Prostate Volume withPost Micturition Residual Volume in BenignProstate Hyperplasia. RADS Journal of Pharmacyand Pharmaceutical Sciences, 6(2), 107-112.

2. American Urological Association \%J WashingtonDAUA. (2010). American Urological Associationguideline: management of benign prostatichyperplasia (BPH).

3. Hassanzadeh, K., Yavari-kia, P., Ahmadi-Asrbadr,Y., \& Nader-Abbasi, F. (2010). Non-obstructivelower urinary tract symptoms versus prostatevolume in benign prostatic 
hyperplasia. Pakistan.journal of biological sciences: PJBS, 13(23), 1129- 1134.

4. Jung, J. H., Ahn, S. V., Song, J. M., Chang, S. J., Kim, K. J., Kwon, S. W., ‥ \&Koh, S. B. (2016). Obesity as a risk factor for prostatic enlargement: a retrospective cohort study in Korea. International neurourology journal, 20(4), 321.

5. Roehrborn, C. G. (2005). Benign prostatic hyperplasia: an overview. Reviews in urology, 7(Suppl 9), S3.

6. Ojewola, R. W., Oridota, E. S., Balogun, O. S., Alabi, T. O., Ajayi, A. I., Olajide, T. A., ... \&Ogundare, E. O. (2017). Prevalence of clinical benign prostatic hyperplasia amongst communitydwelling men in a South-Western Nigerian rural setting: A cross-sectional study. African Journal of Urology, 23(2), 109-115.

7. Lee, C., Kozlowski, J. M., \&Grayhack, J. T. (1995). Etiology of benign prostatic hyperplasia. Urologic Clinics of North America, 22(2), 237-246.

8. Michael, Ng, K.M.B. (2020). Benign Prostatic Hyperplasia. National Library of Medicine.

9. Bhavsar, A., Verma, SJBri. (2014). Anatomic imaging of the prostate, 2014.

10. 10. Lin, P. H., \& Freedland, S. J. (2015). Lifestyle and LUTS: what is the correlation in men?. Current opinion in urology, 25(1), 1.

11. Wei JT, Calhoun E, Jacobsen SJ et al (2005) Urologic Diseases in America project: benign prostatic hyperplasia. $J$ Urol 1256(4):156-159

12. Flegal KM, Carrol MD, Ogden CL, Johnson CL (2002) Prevalence and trends in obesity among US adults, 19992000. J Am Med Assoc 288:1723-1727

13. Wang S, Mao Q, Lin Y, Wu J, Wang X, Zheng X (2012) Body mass index and risk of BPH: a meta-analysis. Prostate Cancer Prostatic Dis 15:265-272

14. Chughtai B, Lee R, Te A, Kaplan S (2011) Role of inflammation in benign prostatic hyperplasia. Rev Urol 13:147-150

15. Penna G, Fibbi B, Amuchastegui S, Cossetti C, Aquilano F, Laverny $G$ (2009) Human benign prostatic hyperplasia stromal cells as inducers and targets of chronic immunemediated inflammation. J Immunol 182:4046-4064

16. Williams G (2012) Aromatase up-regulation, insulin and raised intracellular estrogens in men, induced adiposity, metabolic syndrome and prostate disease. Mol Cell Endocrinol 351:269-278
17. Lee S, Min HG, Choi SH, Kim YJ et al (2006) Central obesity as a risk factor for prostatic hyperplasia. Obesity 14:172-179

18. Matsuda T, Abe H, Suda K, Rinsho B (2004) Relation between benign prostatic hyperplasia and obesity and estrogen. Jpn J ClinPathol 52(4):291-294

19. Kim JM, Song PH, Kim HT, Moon KH (2011) Effect of obesity on prostatespecific antigen, prostate volume, and international prostate symptom score in patients with benign prostatic hyperplasia. Korean J Urol 52(6):401-405

20. Fowke JH, Motley SS, Cookson MS, Conception R, Chang SS, Williams ML, Smith Jr JA (2007) The association between body size, prostate volume and prostate-specific antigen. Prostate Cancer Prostatic Dis 10:137-142

21. Xie LP, Bai $Y$, Zhang XZ, Zheng XY, Yao KS, Xu L, Zeegers MP (2007) Obesity and benign prostatic enlargement: a large observational study in China. Urology 69(4):680-684

22. Fowke JH, Koyama T, Fadare O, Clark PE (2016) Does inflammation mediate the obesity and $\mathrm{BPH}$ relationship? An epidemiologic analysis of body composition and inflammatory markers in blood, urine, and prostate tissue, and the relationship with prostate enlargement and lower urinary tract symptoms. PLOS ONE 11(6):e0156918. https://doi.org/10.1371/jounal.pone0156918.ecollection.

23. Raza, I., Mukhtar, S., Kamran, MJTPMJ. (2017). Benign prostatic hyperplasia, 24(03):445-52

24. 18. Yue, L., Ge, Y., Wang, T., Ge, M., Zhang, C., \& Zhang, W. (2018). The correlation between body mass index and prostatic-related parameters in men 40 years or older in Zhengzhou. The Aging Male.

25. Consultation, W. E. (2004). Appropriate body-mass index for Asian populations and its implications for policy and intervention strategies. Lancet (London, England), 363(9403), 157-163.

26. Tyloch, J.F., Wieczorek, APJJoU. (2017). The standards of an ultrasound examination of the prostate gland. Part 2, 17(68):43

27. Yelsel, K., Alma, E., Eken, A., Gülüm, M., Erçil, H., \&Ayyıldız, A. (2015). Effect of obesity onlnternational Prostate Symptom Score and prostate volume. Urology annals, $7(3)$, 371.

28. Chughtai, B., Forde, J. C., Thomas, D. D. M., Laor, L., Hossack, T., Woo, H. H., ...\& Kaplan, S. A.(2016). Benign prostatic hyperplasia. Nature reviews Disease primers, 2(1), $1-15$. 